Gut, 1978, 19, 321-326

\title{
Intestinal phase of gastric secretion in patients with duodenal ulcer
}

\author{
S. J. KONTUREK ${ }^{1}$, N. KWIECIEN, W. OBTUŁOWICZ, E. SITO, AND J. OLEKSY
}

From the Institute of Physiology, Medical Academy, Kraków, and District Hospital, Kraków, Poland

SUMMARY In 10 healthy subjects and 10 duodenal ulcer patients the intestinal phase of gastric acid secretion was studied by intraduodenal infusion of a $10 \%$ liver extract meal (pH 7) at $400 \mathrm{ml} / \mathrm{h}$ for three hours. A gastroduodenal double lumen tube with two balloons was used to block the pylorus and to prevent duodenogastric reflux. Gastric acid response to a duodenal meal of liver extract reached a peak at the end of the first hour of infusion of the extract and was then followed by a relatively well-sustained plateau. When the figure was normalised as a percentage of peak response to pentagastrin it was about $45 \%$ in healthy subjects and $63 \%$ in duodenal ulcer patients. Serum gastrin concentration increased significantly during a duodenal meal of liver extract only in duodenal ulcer patients and not in healthy subjects. The combination of the duodenal meal of liver extract with pentagastrin infusion resulted in a significantly greater increase in acid output in duodenal ulcer patients than in healthy controls. Duodenal perfusion with a liver extract meal in which the $\mathrm{pH}$ was gradually decreased caused a $\mathrm{pH}$-dependent reduction in acid output, but not in serum gastrin, both in the duodenal ulcer patients and in healthy subjects. This study shows that the intestinal phase in man results in a potent gastric acid stimulation which is $\mathrm{pH}$-dependent, greatly augmented by pentagastrin, and mole vigorous in duodenal ulcer patients than in healthy controls.

An important feature of duodenal ulcer disease is significant secretion of gastric acid and pepsin not only after a meal but also in the interdigestive period (Wormsley and Grossman, 1965; Baron, 1973). This may simply reflect a sustained neurohormonal 'drive' of the oxyntic glands but it might also be ascribed to prolonged intestinal stimulation of gastric secretion. The intestinal phase, however, has been characterised rather as 'turning off' gastric secretion due to the intestinal release of various enterogastrones and stimulatory aspects of this phase have been generally considered as negligible. There are few studies on this subject in man and the results are contradictory. Ippoliti et al. (1976) reported recently that duodenal perfusion with a peptone meal results in a marked stimulation of gastric acid secretion without a significant rise in the level of serum gastrin. It has been concluded that there is a distinct intestinal

\footnotetext{
${ }^{1}$ Address for correspondence: Professor Dr S. J. Konturek, Institute of Physiology, 16 Grzegórzecka St, 31-531 Kraków, Poland.
}

Received for publication 10 October 1977 phase of gastric secretion in man but that it is probably not mediated by gastrin. On the other hand, Grabner et al. (1976) perfused the jejunum with various meals such as liver extract, meat extracts, or acetylcholine solution, but failed to evoke significant stimulation of gastric secretion.

This study was designed to establish the existence of the intestinal phase of gastric secretion in man and to compare it in healthy subjects and duodenal ulcer patients.

\section{Methods}

Ten healthy male subjects (mean age 21 years, range 20-22 years and mean weight $72 \mathrm{~kg}$, range $69-75 \mathrm{~kg}$ ) and 10 male patients (mean age 22 years, range 21-23 years and mean weight $68 \mathrm{~kg}$, range 66-71 kg) with well-established chronic duodenal ulcer disease were repeatedly examined. All patients were in clinical remission when their study period began. Each subject gave informed consent.

In all tests a double lumen gastroduodenal tube modified with two balloons was passed and a few hours later positioned under fluoroscopic control 
with the tip at the junction of the third and fourth parts of the duodenum (Fig. 1). The balloons straddling the pylorus were inflated with $20 \mathrm{ml}$ of air to prevent duodenogastric reflux. Inflation of the balloons did not cause any sensation or discomfort.

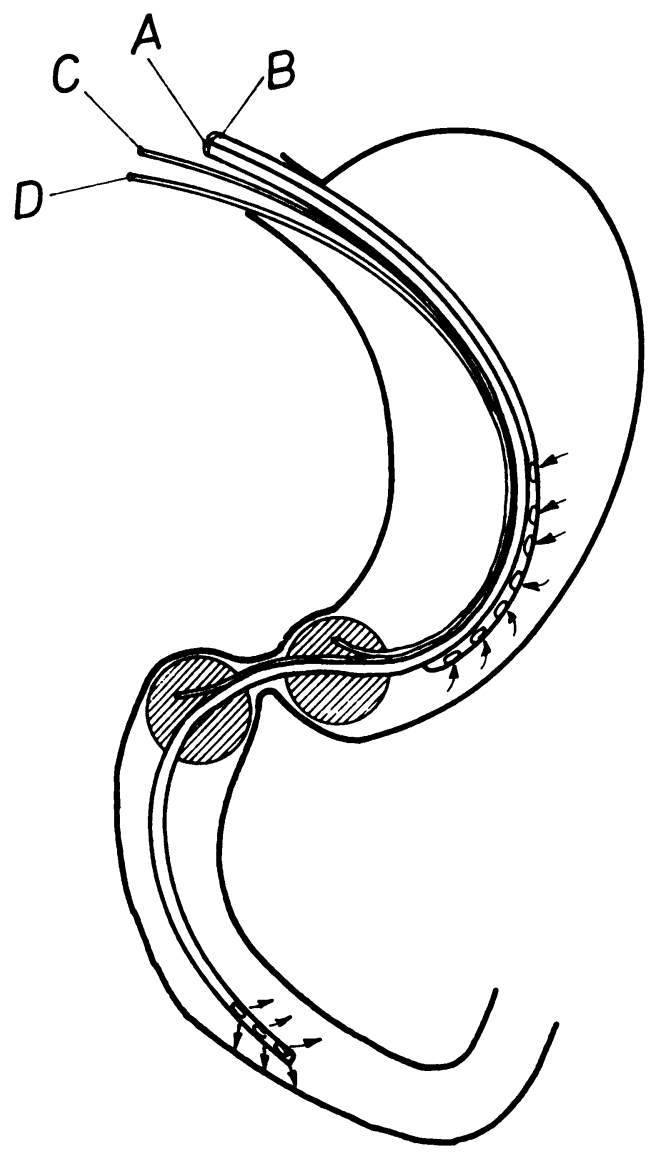

Fig. 1 Diagram showing the method used in intraduodenal instillation experiments. Intraduodenal instillation $(A)$ and gastric aspiration $(B)$ were made via a double lumen tube. Other polyethylene tubes $(C$ and $D)$ were connected with rubber balloons which were inflated with air to prevent duodenogastric reflux.

Several types of test were performed in random order on each subject: (1) a $10 \%$ liver extract (Reheis Chemical Co., Chicago, Ill.) meal adjusted to $\mathrm{pH} 7.0$ (osmolality about $600 \mathrm{mOsm} / \mathrm{kg}$ ) was instilled into the duodenum at a rate of $400 \mathrm{ml} / \mathrm{h}$ for three hours; in control tests $0 \cdot 3 \mathrm{M} \mathrm{NaCl}$ solution was instilled into the duodenum for the period of examination; (2) a $10 \%$ liver extract meal was adjusted to selected $\mathrm{pH}$ varying from 7.0 to 2.0 and instilled into the duodenum at a rate of $400 \mathrm{ml} / \mathrm{h}$ at this same $\mathrm{pH}$ for 45 minutes; (3) pentagastrin was infused intravenously in a constant dose of 2 $\mu \mathrm{g} / \mathrm{kg} / \mathrm{h}$, a dose that had been previously shown (Konturek et al., 1975) to induce maximal acid output (MAO); the MAO was taken as the sum of the four highest consecutive 15 minute outputs; (4) pentagastrin was infused intravenously for three hours and after one hour of infusion when the gastric acid output reached a plateau a liver extract meal was instilled intraduodenally at a rate of $400 \mathrm{ml} / \mathrm{h}$ for the rest of the experiment. All duodenal meals contained phenol red $(50 \mu \mathrm{g} / \mathrm{ml})$, which was used to measure duodenogastric reflux.

In all tests gastric juice was collected by a standard aspiration technique. Acid and pepsin concentrations and outputs were determined by the methods previously described (Konturek et al., 1975). The amounts of phenol red which refluxed from the duodenum into the stomach were measured and expressed as percentages of the amount instilled into the duodenum during each 15 minute period. Phenol red concentration was measured spectrophotometrically at $520 \mathrm{~nm}$ after being alkalinised to $\mathrm{pH} 11 \cdot 5$.

Venous blood samples were drawn for gastrin determinations in the basal state and at 30-45 minute intervals throughout the tests with intraduodenal instillation of test meals. Serum gastrin was measured by radioimmunoassay (Yalow and Berson, 1970). Antibodies to gastrin were obtained by immunising rabbits with synthetic human gastrin I (G-2-17, ICI, England) covalently coupled to bovine serum albumin according to McGuigan (1968) and used in a final dilution of 1:300 000. Monoiodinated synthetic human gastrin I (G-17) was used as tracer and G-17 as standard. The separation of antibody-bound from free hormone was carried out by dextran-coated charcoal and the labelled free and bound hormone was counted in an automatic gamma scintillation counter (Wallac, LKB, Sweden). The antibody used in this study is immunologically reactive with all known molecular forms of gastrin. The within-assay variation determined by repeated measurements of two pools of sera ranged from 2.2 to $5.0 \%$ and between assay variation was 6.0 to $13.0 \%$. All determinations were performed in duplicate. The immunoassay system was sufficiently sensitive to detect $5 \mathrm{pg} / \mathrm{ml}$ of serum gastrin.

The results are expressed as the mean plus and minus the SEM. The significance of the differences in the acid and pepsin outputs and serum gastrin levels between groups of different subjects was determined by the Mann-Whitney test (Siegel, 1956). A P value of less than 0.05 was considered to be statistically significant. 


\section{Results}

Intraduodenal instillation of $0.3 \mathrm{M} \mathrm{NaCl}$ in control tests did not affect the gastric acid or serum gastrin level and these results were omitted for the sake of clarity in presentation. Intraduodenal instillation of a $10 \%$ liver extract meal at a constant rate of $400 \mathrm{ml} / \mathrm{h}$ caused an increase in gastric acid output which in healthy subjects and duodenal ulcer patients reached $45 \%$ and $63 \%$ of the pentagastrin MAO, respectively. The difference in the mean peak secretory response to intestinal liver extract meal perfusion normalised as a percentage of the pentagastrin MAO between the healthy subjects and duodenal ulcer patients was statistically significant. Acid response started to increase soon after the onset of intestinal perfusion of a liver extract meal, reached a peak at the end of the first hour, and then remained on a well-sustained plateau for the rest of the examination (Fig. 2). Intestinal perfusion of a liver extract meal resulted also in a marked rise in pepsin secretion both in healthy subjects and duodenal ulcer patients, but the difference in pepsin outputs between these two groups of subjects was not statistically significant (Table). The serum gastrin level tended to increase when the liver extract meal was instilled into the duodenum but the increase was statistically significant only in duodenal ulcer patients and not in healthy subjects.

Intestinal perfusion with the liver extract meal adjusted to gradually decreasing $\mathrm{pH}$ levels from 7.0 to 2.0 reduced acid response: at $\mathrm{pH} 2.0$ it fell to basal in healthy subjects and to about $30 \%$ of the initial peak output (at $\mathrm{pH} \mathrm{7.0)}$ in duodenal ulcer patients. Serum gastrin concentration did not change significantly with acidification of the intes-

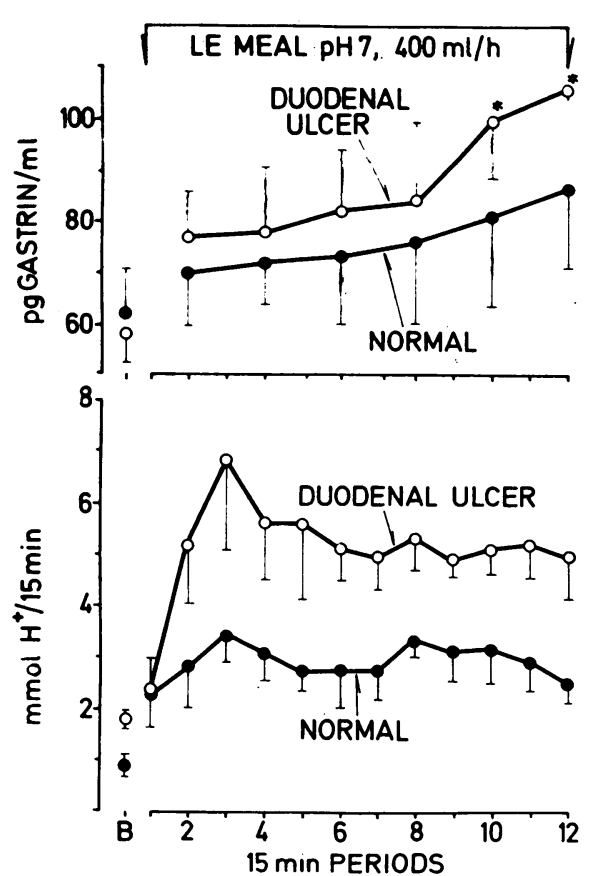

Fig. 2 Effect of intraduodenal instillation of $10 \%$ liver extract meal at $400 \mathrm{ml} / \mathrm{h}$ on gastric acid and serum gastrin in healthy subjects and in duodenal ulcer patients. In this and subsequent figures each line is the mean of 10 tests on each of 10 subjects. Vertical lines indicate mean \pm 1 SEM.

tinal meal at any pH level (Fig. 3).

The combination of the duodenal liver extract meal with pentagastrin infusion caused a further rise in acid output above that induced by penta-

Table Peak gastric acid and pepsin responses to intestinal LE meal alone, to pentagastrin, to intestinal LE meal combined with pentagastrin or to intestinal LE meal adjusted to various pHs (means $\pm S E M$ or percentage of pentagastrin $M A O$ )

\begin{tabular}{|c|c|c|c|c|c|c|c|c|}
\hline & \multicolumn{4}{|l|}{ Acid secretion } & \multicolumn{4}{|c|}{ Pepsin secretion } \\
\hline & \multicolumn{2}{|l|}{ Normals } & \multicolumn{2}{|l|}{$D U$ patients } & \multicolumn{2}{|l|}{ Normals } & \multicolumn{2}{|l|}{$D U$ patients } \\
\hline & $\mathrm{mmol} \mathrm{H}^{+} / \mathrm{h}$ & $\% p M A O$ & mmol $H^{+} / h$ & $\% p M A O$ & mmol $H^{+} / h$ & $\% p M A O$ & $\mathrm{mmol} \mathrm{H}^{+} / \mathrm{h}$ & $\% p M A O$ \\
\hline $\begin{array}{l}\text { Intestinal } \\
\text { LE meal }\end{array}$ & $11 \cdot 51 \pm 1 \cdot 31$ & 45 & $25.03 \pm 1.85 \ddagger$ & 63 & $89 \pm 11$ & 98 & $121 \pm 8$ & 124 \\
\hline Pentagastrin & $25 \cdot 57 \pm 3 \cdot 34$ & 100 & $39 \cdot 62 \pm 2 \cdot 76 \ddagger$ & 100 & $91 \pm 12$ & 100 & $97 \pm 8$ & 100 \\
\hline $\begin{array}{l}\text { LE meal at } \\
\text { pH } 7 \\
\text { pH } 5 \\
\text { pH } 3 \\
\text { pH } 2\end{array}$ & $\begin{array}{c}10.4 \pm 1.2 \\
10.8 \pm 1.3 \\
4.4 \pm 0.8 \dagger \\
1 \cdot 2 \pm 0.2 \dagger\end{array}$ & $\begin{array}{r}40 \\
42 \\
17 \\
5\end{array}$ & $\begin{array}{c}18.4 \pm 2.1 \\
17.6 \pm 1.9 \\
12.6 \pm 2.2 \\
5.5 \pm 1.2 \dagger\end{array}$ & $\begin{array}{l}46 \\
44 \\
31 \\
13\end{array}$ & $\begin{array}{r}95 \pm 17 \\
99 \pm 14 \\
104 \pm 21 \\
82 \pm 13\end{array}$ & $\begin{array}{r}104 \\
108 \\
114 \\
90\end{array}$ & $\begin{array}{l}129 \pm 14 \\
135 \pm 20 \\
138 \pm 17 \\
120 \pm 23\end{array}$ & $\begin{array}{l}132 \\
139 \\
142 \\
123\end{array}$ \\
\hline
\end{tabular}

*Significant $(P<0.05)$ increase over the pentagastrin MAO.

†Significant $(\mathrm{P}<0.05)$ decrease below the output at $\mathrm{pH} 7$.

¥Significant $(P<0.05)$ increase in duodenal ulcer patients over the value in healthy subjects. 

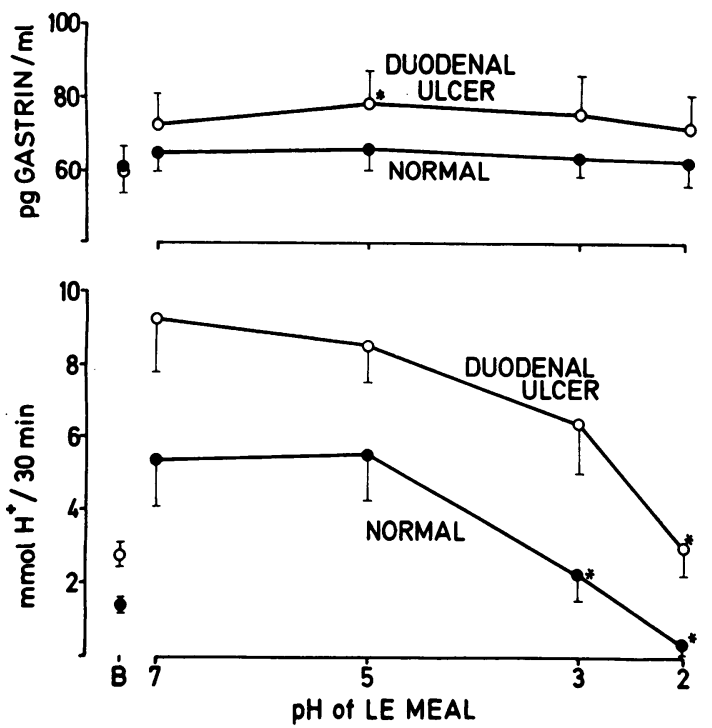

Fig. 3 Gastric acid and serum gastrin responses to a liver extract meal at $\mathrm{pH}$ levels varying from $7 \cdot 0$ to $2 \cdot 0$.

gastrin alone. In healthy subjects this rise was statistically significant only during one 15 minute period at the beginning of the instillation of liver extract and then acid output tended to return towards the control values. In duodenal ulcer patients this rise was significant almost throughout the instillation of the liver extract meal and was about twice as high as that in healthy controls (Fig. 4).

Pepsin outputs in response to a combination of intravenous pentagastrin and an intraduodenal meal of liver extract were significantly higher than to pentagastrin alone. Again, in healthy subjects, this increase was significant only for one 15 minute period, while in duodenal ulcer patients it was significant throughout the time that the liver extract meal was being instilled (Fig. 5).

In 920 of the 96015 minute periods there was no phenol red in the gastric aspirate, indicating no detectable duodenogastric reflux; in the remaining 40 there was less than $5 \%$.

\section{Discussion}

This study shows conclusively that there is a distinct intestinal phase of gastric secretion in healthy subjects and in duodenal ulcer patients in response to intestinal perfusion with a meal of liver extract.

The mechanism of the potent intestinal stimulation of gastric secretion has been little studied in man and most of the information available has been derived from animal experiments (Buxton et al., 1972; Debas et al., 1975; Konturek et al., 1976). It has been suggested that the intestinal phase of stimulation of gastric acid and serum gastrin could be accounted for by the alleged release from the gut of two hormonal substances, entero-oxyntin (Debas et al., 1975), which directly stimulates the oxyntic glands, and enterobombesin, which stimulates the release of antral gastrin and gastric acid secretion (Erspamer and Melchiorri, 1975).

Our study demonstrates that, in healthy subjects, the stimulation of gastric acid secretion by an intestinal meal reaches about $45 \%$ of the pentagastrin MAO but it is not accompanied by a significant rise in serum gastrin level. Duodenal ulcer patients showed significantly higher gastric acid

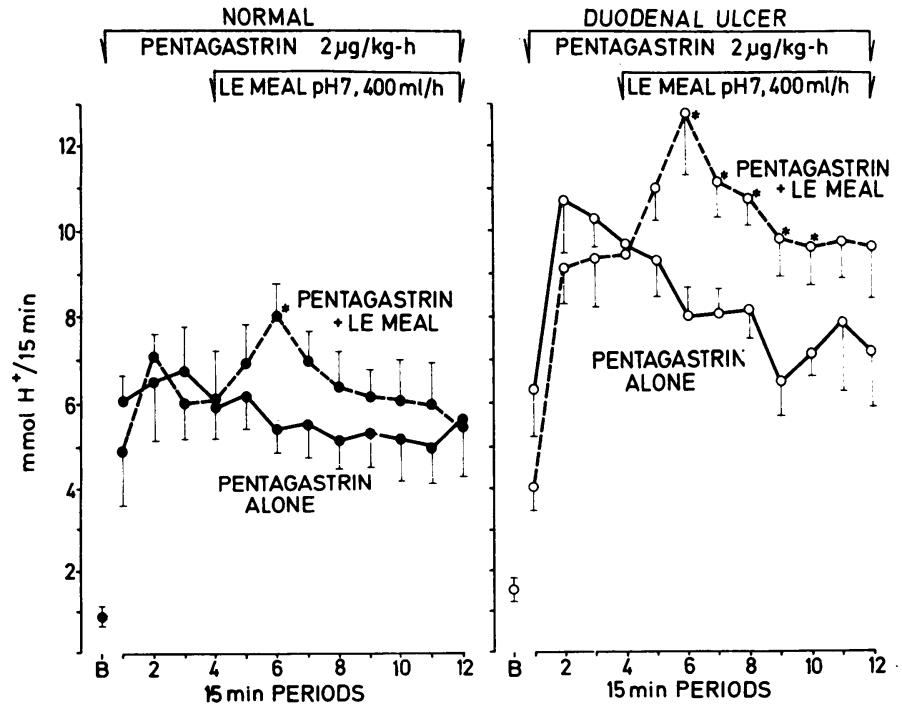

Fig. 4 Effect of intravenous pentagastrin alone $(2 \mu \mathrm{g} / \mathrm{kg}-\mathrm{h})$ or combined with intraduodenal liver extract meal on acid outputs in 10 healthy subjects and 10 duodenal ulcer patients. 


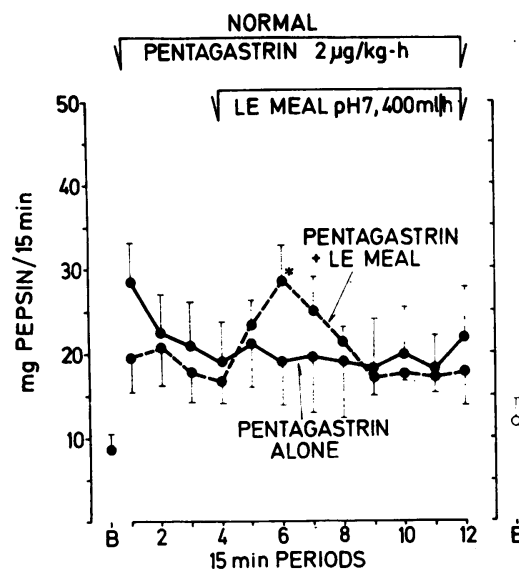

DUODENAL ULCER
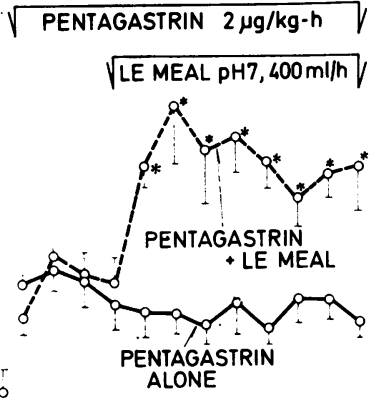

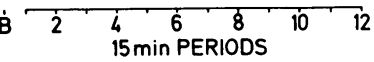

Fig. 5 Pepsin outputs in tests as in Fig. 4. response to an intestinal meal, reaching about $63 \%$ of the pentagastrin MAO and associated with a significant rise in serum gastrin level. This suggests that during intestinal stimulation, as during cephalic or gastric stimulation (Konturek, 1976), both the oxyntic exocrine and the gastrin endocrine parts of the stomach react more vigorously in duodenal ulcer patients than in healthy controls. As our present study was performed on rather small groups of subjects it remains to be established in larger groups whether this represents a general feature of duodenal ulcer disease or a separate entity occurring only in some of these patients.

The intestinal stimulation of gastric secretion by the liver extract meal was found to be $\mathrm{pH}$-dependent. When the intestinal meal was acidified to $\mathrm{pH} 2 \cdot 0$, gastric acid secretion was almost completely inhibited in healthy subjects and partially inhibited in duodenal ulcer patients. This inhibition was probably not dependent upon the suppression of gastrin release as serum gastrin levels were not significantly affected. Plasma secretin level was not measured in this study but it is expected that it would be increased at lower $\mathrm{pH}$ of the intestinal meal (Isenberg et al., 1977) and would contribute to the observed inhibition of gastric secretion (Konturek et al., 1974). There may be also a secretin-independent neural reflex mechanism triggered by acid in the upper part of the duodenum and involved in the inhibition of gastric secretion by an acidified duodenal meal. Our finding that the inhibitory effect of acidified duodenal meal in duodenal ulcer patients was less pronounced than in healthy controls indicates a possible abnormality of duodenal autoregulation of gastric secretion in these patients. A similar abnormality of antral autoregulation of gastric secretion was reported previously in duodenal ulcer patients and it was suggested that it was an important factor in the pathogenesis of duodenal ulcer disease (Walsh et al., 1975).

One of the criteria which was used in animals to distinguish the intestinal phase hormone (enterooxyntin) from non-specific stimulants such as antral type gastrin or cholecystokinin is the augmentation of the maximal response to pentagastrin or histamine (Debas et al., 1975; Konturek et al., 1976). It appears that this criterion can also be demonstrated in humans, particularly in duodenal ulcer patients, who show marked, prolonged, and highly significant augmentation of both gastric acid and pepsin responses to pentagastrin after a duodenal liver extract meal. The fact that the maximal acid response to pentagastrin can be augmented by an intestinal meal suggests that the mechanism of this augmentation is not gastrin-dependent but mediated by other stimulants of humoral or neural character. As the degree of this augmentation was much more marked in duodenal ulcer patients than in healthy controls it may be concluded that intestinal stimulatory mechanisms are hyper-reactive and possibly in part responsible for the increase of the interdigestive gastric acid outputs reported in these patients.

\section{References}

Baron, J. H. (1973). The clinical application of gastric secretion measurements. Clinics in Gastroenterology, 2, 293-314.

Buxton, B., Wasunna, A. E. O., Bedi, B. S., and Gillespie, I. E. (1972). Role of the jejunum and the ileum in the acid response of dogs to a meal. Gastroenterology, 63, 270-272.

Debas, H. T., Slaff, G. F., and Grossman, M. I. (1975). Intestinal phase of gastric acid secretion: augmentation of maximal response of Heidenhain pouch to gastrin and histamine. Gastroenterology, 68, 691-698.

Erspamer, V., and Melchiorri, P. (1975). Actions of bombesin on secretions and motility of the gastrointestinal tract. 
In Gastrointestinal Hormones, p. 575. Edited by J. C. Konturek, S. J., Biernat, J., and Oleksy, J. (1974). Serum Thompson. University of Texas Press: Austin.

Grabner, P., Semb, L. S., Schrumpf, E., and Myren, J. (1976). The intestinal phase of gastric secretion. Scandinavian Journal of Gastroenterology, 11, 415-419.

Ippoliti, A. F., Maxwell, V., and Isenberg, J. I. (1976). Demonstration of the intestinal phase of gastric acid secretion in man (Abstract). Gastroenterology, 70, 896.

Isenberg, J. I., Cano, R., and Bloom, S. R. (1977). Effect of graded amounts of acid instilled into the duodenum on pancreatic bicarbonate secretion and plasma secretin in duodenal ulcer patients and normal subjects. Gastroenterology, 72, 6-8.

Konturek S. J. (1976). Pathophysiology of gastric secretion. In 10 International Congress of Gastroenterology, p. 93. Edited by I. Magyar and I. Wittman. OKISZ Labor Nyomda: Budapest.

Konturek, S. J., Biernat, J., Kwiecien, N., and Oleksy, J. (1975). Effect of glucagon on meal-induced gastric secretion in man. Gastroenterology, 68, 448-454. gastrin and gastric acid responses to meals at various $\mathbf{p H}$ levels in amn. Gut, 15, 526-530.

Konturek, S. J., Kaess, H., Kwiecien, N., Radecki, T., Dorner, M., and Teckentrupp, V. (1976). Characteristics of intestinal phase of gastric secretion. American Journal of Phy'siology, 230, 335-340.

McGuigan, J. E. (1968). Immunochemical studies with synthetic human gastrin. Gastroenterology, 54, 1005-1011.

Siegel, S. (1956). Nonparametric Statistics for the Behavioral Sciences. McGraw-Hill: New York.

Walsh, J. H., Richardson, C. T., and Fordtran, J. S. (1975). pH-dependence of acid secretion and gastrin release in normal and ulcer subjects. Journal of Clinical Investigation, 55, 462-468.

Wormsley, K. G., and Grossman, M. I. (1965). Maximal histalog test in control subjects and patients with peptic ulcer. Gut, 6, 427-435.

Yalow, R. S., and Berson, S. A. (1970). Radioimmunoassay of gastrin. Gasiroenterology, 58, 1-14. 